\title{
Odporność odlewniczego stopu magnezu AZ91 na korozję elektrochemiczną
}

\author{
Resistance of cast AZ91 magnesium alloy \\ to electrochemical corrosion
}

\section{Streszczenie}

W artykule przedstawiono wyniki testów odporności na korozję elektrochemiczną odlewniczego stopu magnezu AZ91. Obserwacjom poddano materiał rodzimy i złącza spawane wykonane metodą TIG (141). Jako kryterium odporności na korozję elektrochemiczną przyjęto ubytek masy i czas korozji przy określonych stężeniach roztworu kwasu $\mathrm{H}_{2} \mathrm{SO}_{4}$. Stwierdzono, że wzrost stężenia roztworu kwasu wpływa znacząco na szybkość korozji stopu powodując tym samym większą degradację jego powierzchni i większy ubytek masy. Zauważono również, że prędkość korozji maleje w przypadku wydłużenia czasu eksperymentu. Po czasie $72 \mathrm{~h}$ prędkość ta spada poniżej $0,1 \mathrm{~g} /\left(\mathrm{cm}^{2} \cdot\right.$ doba), co spowodowane jest hamowaniem korozji w wyniku zobojętniania się roztworu kwasu.

Słowa kluczowe: stop magnezu AZ91; spawanie; odporność korozyjna

\begin{abstract}
The article presents the results of AZ91 cast magnesium alloy resistance to electrochemical corrosion. The basic material and welding joints obtained by TIG method (141) were evaluated. The mass loss and corrosion time at specific concentrations of the $\mathrm{H}_{2} \mathrm{SO}_{4}$ acid solution were assumed as a criterion of resistance to electrochemical corrosion. It was found that an increase in the acid solution concentration significantly affects the rate of corrosion of alloy, thus causing a greater degradation of its surface and a higher mass loss. It was also noticed that the corrosion rate decreases when the experiment time is extended. After $72 \mathrm{~h}$, this speed drops below $0.1 \mathrm{~g} /\left(\mathrm{cm}^{2} \cdot\right.$ day $)$, which is caused by the inhibition of the corrosion as a result of the neutralization of the acid solution.
\end{abstract}

Keywords: AZ91 magnesium alloy; welding; corrosion resistance

\section{Wstęp}

Ze względu na konieczność stosowania lekkich elementów konstrukcyjnych w przemyśle lotniczym i motoryzacyjnym stopy magnezu od lat cieszą się sporym powodzeniem. Wysoki stosunek wytrzymałości materiału do masy i przewodności cieplnej umożliwia przenoszenie podobnych obciążeń statycznych czy dynamicznych w porównaniu np. do stali. Stopy na bazie magnezu dzieli się na dwie grupy: odlewnicze oraz do przeróbki plastycznej. Najpopularniejszym, jak również najczęściej stosowanym odlewniczym stopem magnezu jest AZ91 zawierający aluminium (do $9 \%$ ), cynk (do 1\%) i mangan (do 0,35\%). Zawartość aluminium w stopach magnezu zwiększa wytrzymałość na rozciąganie i twardość, dodatkowo poprawia lejność stopów oraz zwiększa różnicę pomiędzy temperaturą likwidus i solidus. Cynk dodany w ilości do 1\% zwiększa wytrzymałość na rozciąganie w temperaturze pokojowej, a także zmniejsza rozpuszczalność aluminium w roztworze stałym.

Technologie spawalnicze w stopach magnezu są stosowane do łączenia elementów ze stopów przerabianych plastycznie oraz do łączenia odlewów w konstrukcje. Wykorzystuje się je także do naprawy wad w odlewach powstałych w procesie odlewania lub w wyniku obróbki mechanicznej, jak również do regeneracji zużytych odlewów. Złącza wykonywane ze stopów magnezu powinny mieć odpowiednie właściwości, aby móc spełniać wymogi stawiane konstrukcjom. Przy spawaniu stopów magnezu występują trudności związane z właściwościami metalurgicznymi, m.in.: składem chemicznym, dużym przewodnictwem cieplnym, dużym powinowactwem magnezu do tlenu i tworzeniem się tlenku $\mathrm{MgO}$, niską temperaturą parowania stopów oraz szerokim zakresem temperatury pomiędzy temperaturą likwidus i solidus, które decydują o pękaniu materiału. Kolejne trudności wpływające na spawalność odlewniczych stopów magnezu to czynniki konstrukcyjne tj.: rozwiązanie konstrukcyjne odlewu, różnice w grubościach ścianek, stopień złożoności odlewu, sztywność odlewu oraz obecność karbów. Dodatkowo na spawalność wpływ mają czynniki technologiczne, czyli metoda i warunki spawania. Decydują one o ilości wprowadzonego ciepła oraz o szybkości chłodzenia spoiny i strefy wpływu ciepła. Wraz ze wzrostem energii liniowej łuku wzrasta objętość jeziorka ciekłego metalu spoiny oraz szerokość strefy wpływu ciepła. Powoduje to zmianę warunków krysta-

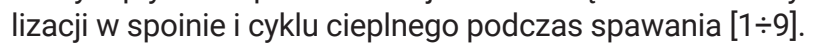

Mgr inż. Katarzyna Łyczkowska - Politechnika Śląska.

Autor korespondencyjny/Corresponding author: katarzyna.lyczkowska@polsı.pl 
Przegląd literatury wskazuje na wiele problemów związanych z naprawą odlewów ze stopów magnezu technikami spawalniczymi, jednak z coraz większym powodzeniem wykorzystuje się je w przemyśle. Dodatkowo, zapotrzebowanie na produkcję odlewów ze stopów Mg przypisuje się pozytywnym wynikom umożliwiającymi rozwiązanie problemów korozyjnych, dzięki wytworzeniu stopów o wysokiej czystości chemicznej, co pozwala na dłuższą eksploatację odlewanych elementów. Niestety brak jest informacji na temat właściwości złączy spawanych z odlewniczych stopów magnezu pracujących w agresywnym środowisku korozyjnym. Istnieje zatem konieczność określenia tych właściwości w symulowanych warunkach eksploatacji $[10 \div 12]$.

\section{Materiał do badań i metodyka}

Próby technologiczne napawania i spawania przeprowadzono na płytach próbnych ze stopu AZ91 o grubości $5 \mathrm{~mm}$ wyciętych z odlewów. Przetopienia wykonano metodą TIG (141) z zastosowaniem materiału dodatkowego o zbliżonym składzie chemicznym. W tym celu wykorzystano źródło FALTIG 400 AC/DC, stosując natężenie prądu o wartości $100 \mathrm{~A}$ i napięcie łuku równe $14 \mathrm{~V}$.

Jako gaz osłonowy zastosowano argon techniczny 99,995 o natężeniu przepływu $10 \mathrm{l} / \mathrm{min}$. Skład chemiczny badanego materiału przedstawiono $\mathrm{w}$ tablicy I.

Tablica I. Skład chemiczny stopu magnezu AZ91

Table I. Chemical composition of AZ91 magnesium alloy

\begin{tabular}{|c|c|c|c|c|}
\hline \multirow{2}{*}{ Stop } & \multicolumn{4}{|c|}{ Pierwiastek stopowy, \% } \\
\cline { 2 - 5 } & $\mathbf{M g}$ & Al & Zn & Mn \\
\hline AZ91 & reszta & 9,0 & 0,7 & 0,29 \\
\hline
\end{tabular}

Do oceny odporności na korozję elektrochemiczną złączy spawanych płyt próbnych ze stopu magnezu zastosowano test zanurzeniowy. Test prowadzono $\mathrm{w}$ temp. $20^{\circ} \mathrm{C}, \mathrm{w}$ roztworze $\mathrm{H}_{2} \mathrm{SO}_{4}$ o różnych stężeniach (1\%, 5\% i 10\%). Próbki

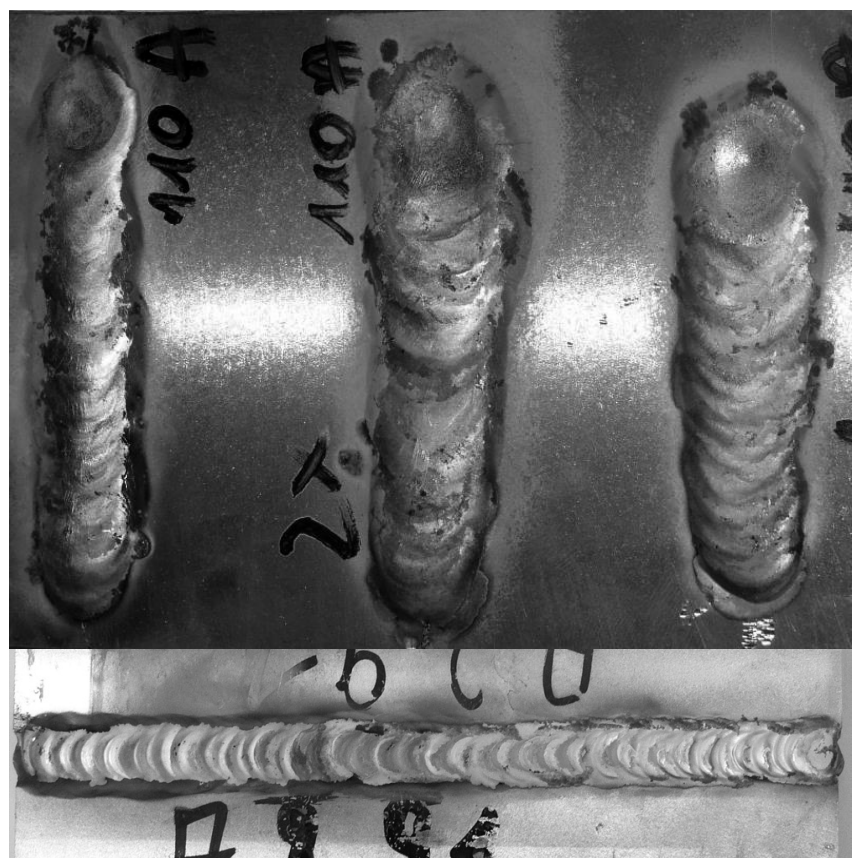

Rys. 1. Złącza spawane i napoiny odlewniczego stopu magnezu AZ91 - widok od strony lica

Fig. 1. Joints and pad welds in magnesium alloy AZ91 casting alloys - view from the face w kształcie prostopadłościanów o wymiarach 10×10x10 mm $\left(1 \mathrm{~cm}^{3}\right)$ wycięte $z$ materiału rodzimego oraz spoiny szlifowane były na papierach ściernych o ziarnistości $600 \mu \mathrm{m}$, odtłuszczane i płukane w alkoholu. Następnie próbki były ważone, co pozwoliło na ustalenie ich masy początkowej $\mathrm{m}_{0}$. Osuszone i zważone próbki były zanurzane w $50 \mathrm{~cm}^{3}$ roztworu testowego przez 1, 3, 24, 48, 72 i 120 h. Po ich wyjęciu, usuwano produkty korozji w roztworze zawierającym $200 \mathrm{~g} / \mathrm{l} \mathrm{CrO}_{3}$ i $10 \mathrm{~g} / \mathrm{l} \mathrm{AgNO}_{3}$ przez 2-5 minut. Po usunięciu produktów korozji, próbki przemywano wodą destylowaną, odtłuszczano w alkoholu i ponownie ważono, ustalając ich masę $\mathrm{m}_{1}$. Dla każdego z wariantów wykonano po 3 pomiary, których wyniki uśredniono. Szybkość korozji Vkor obliczono ze wzoru:

$$
\mathrm{V}_{\mathrm{kor}}=\frac{\Delta \mathrm{m}}{\mathrm{A} \cdot \mathrm{t}}\left[\frac{\mathrm{g}}{\mathrm{cm}^{2} \cdot \mathrm{h}}\right]
$$

gdzie:

$\Delta \mathrm{m}$ - ubytek masy, $\Delta \mathrm{m}=\mathrm{m}_{0}-\mathrm{m}_{1}[\mathrm{~g}]$,

A - pole powierzchni próbki $\left[\mathrm{cm}^{2}\right]$,

$\mathrm{t}$ - czas zanurzenia próbki w roztworze [h].

\section{Wyniki badań}

Jako kryterium odporności na korozję elektrochemiczną przyjęto ubytek masy dla materiału rodzimego przy określonym stężeniu roztworu kwasu. Do tej wartości odnoszone były wyniki testu dla próbek ze spoiny złącza płyty próbnej. Podobną metodykę przyjęto do oceny szybkości korozji spoiny. Wyniki pomiarów ubytku masy oraz obliczeń prędkości korozji w formie graficznej pokazano na rysunku 2.
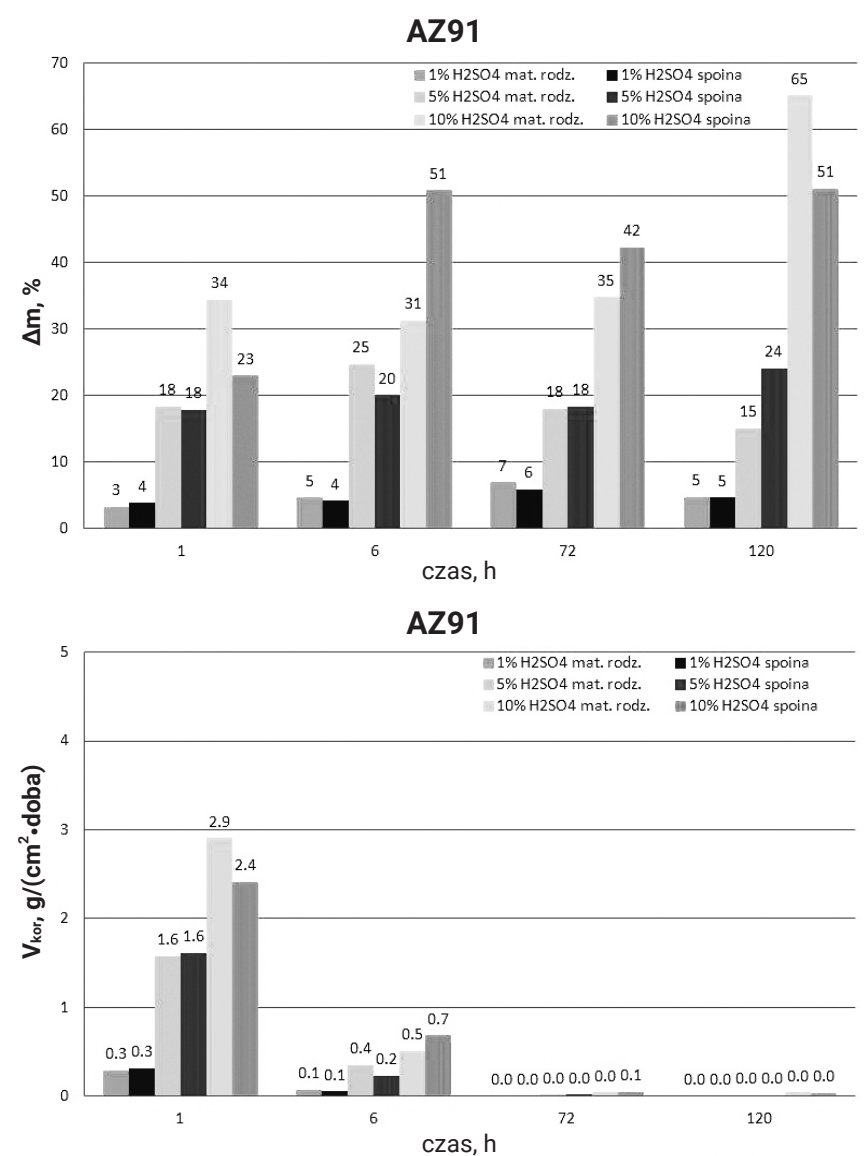

Rys. 2. Wyniki badań odporności na korozję elektrochemiczną złączy spawanych stopu AZ91 w roztworach kwasu $\mathrm{H}_{2} \mathrm{SO}_{4}$ : a) ubytek masy próbki w funkcji czasu badania, b) szybkość korozji w funkcji czasu

Fig. 2. The results of electrochemical corrosion resistance of AZ91 alloy welding joints in $\mathrm{H}_{2} \mathrm{SO}_{4}$ acid solutions: a) weight loss of the sample as a function of test time, b) corrosion rate as a function of time 
Analiza zmian masy w czasie (przez 120 h) próbek wyciętych z materiału rodzimego i spoiny złącza spawanego ze stopu AZ91 po zanurzeniu w $1 \%$ roztworze $\mathrm{H}_{2} \mathrm{SO}_{4}$ wskazuje, że spoina i materiał rodzimy charakteryzują się podobną odpornością na korozję elektrochemiczną (rys. 2a). Ubytek masy próbki wyciętej z materiału rodzimego jest w zakresie od 3 do $7 \%$, a spoiny od 4 do $6 \%$. Rozkłady zmian masy próbek wskazują, że w początkowym okresie (do ok. 1 h) następuje przyrost produktów korozji, co związane jest z ubytkiem masy, odpowiednio dla materiału rodzimego $3 \%$ i $4 \%$ dla spoiny. Po $6 \mathrm{~h}$ masa produktów korozji jest na stałym poziomie (rys. 2a). Potwierdzają to wyniki obliczeń szybkości korozji (rys. 2b). Szybkość korozji narasta do poziomu $0,3 \mathrm{~g} /\left(\mathrm{cm}^{2} \cdot\right.$ doba $)$ po $1 \mathrm{~h}$, a podczas dalszego wytrzymania pró-
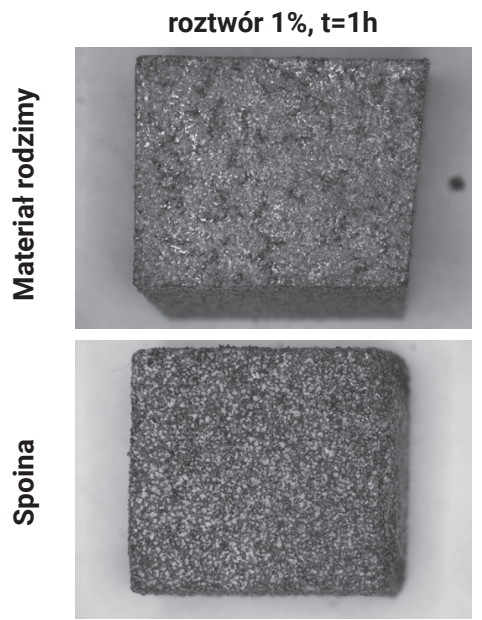
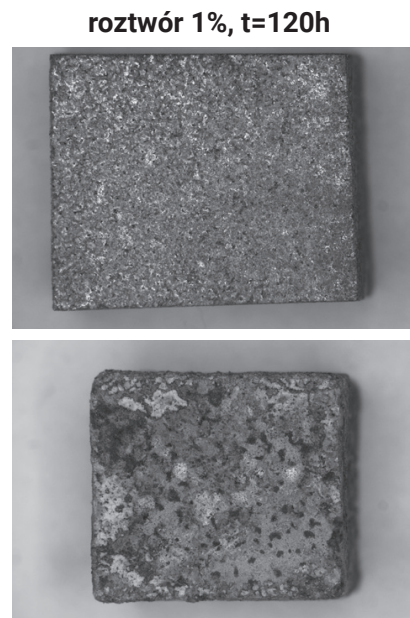
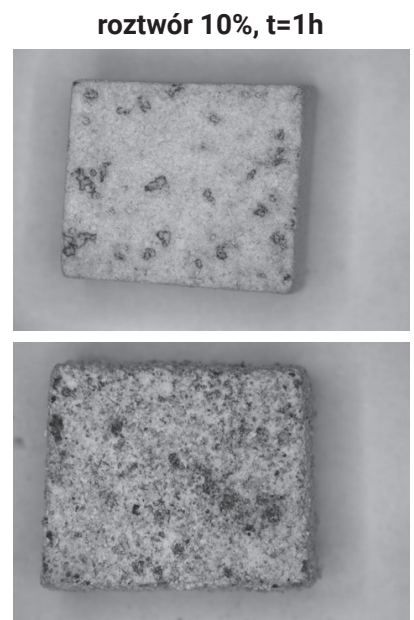
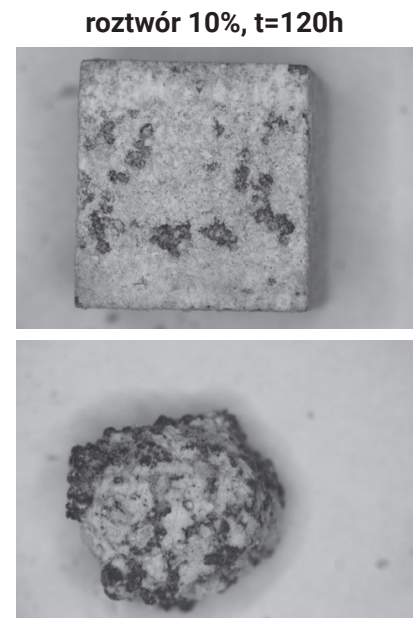

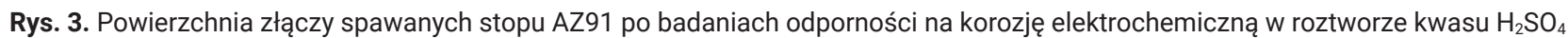
Fig. 3. The surface of welding jonits of the AZ91 alloy after electrochemical corrosion resistance tests in $\mathrm{H}_{2} \mathrm{SO}_{4}$ acid solution

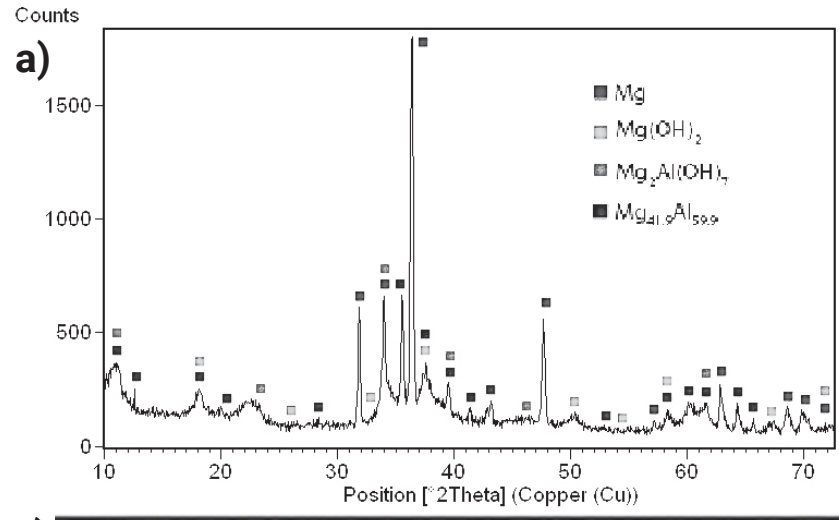

c)

c)
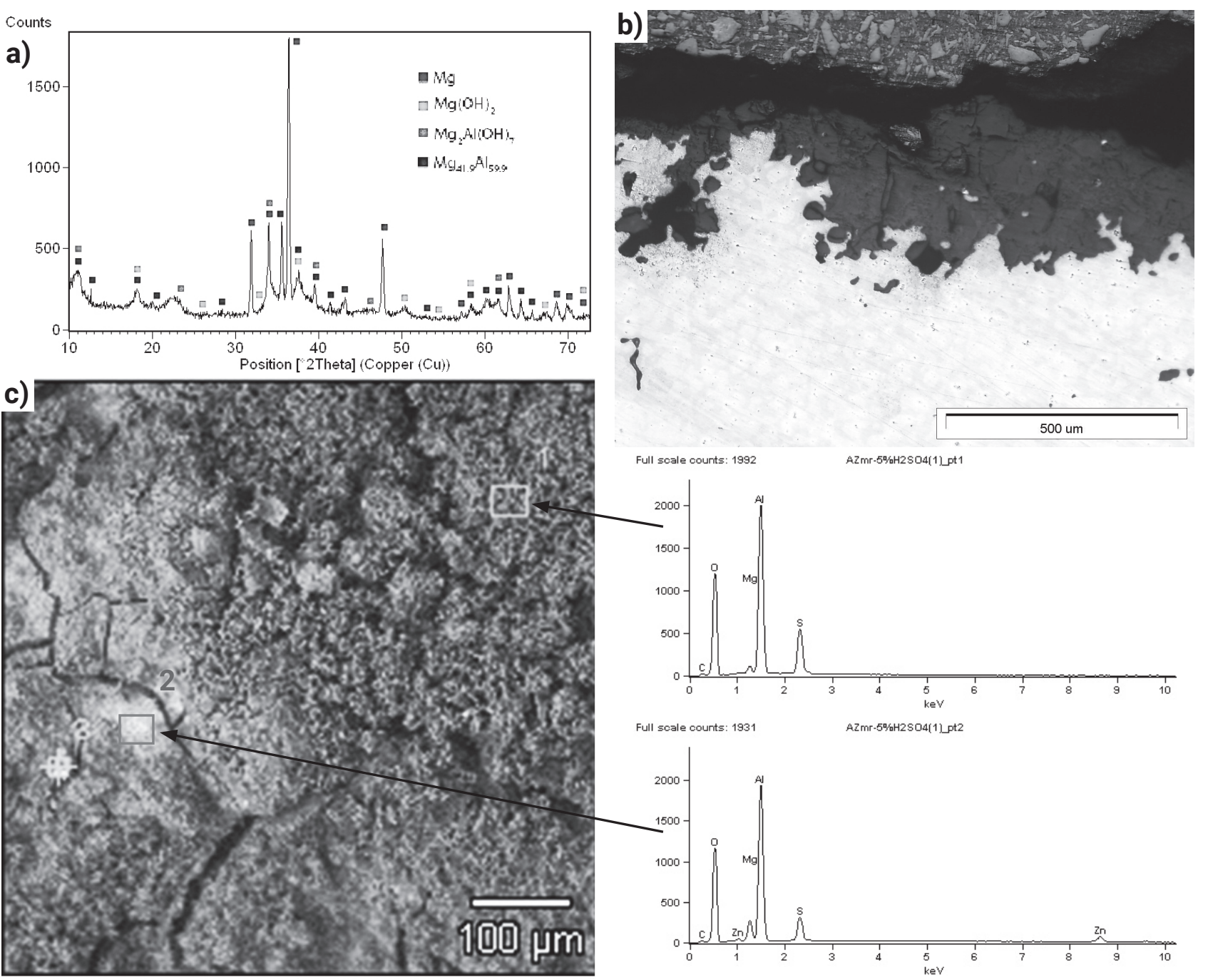

Full soale counts: $1931 \quad$ AZmr-5\%H2SO4[1]_pt2

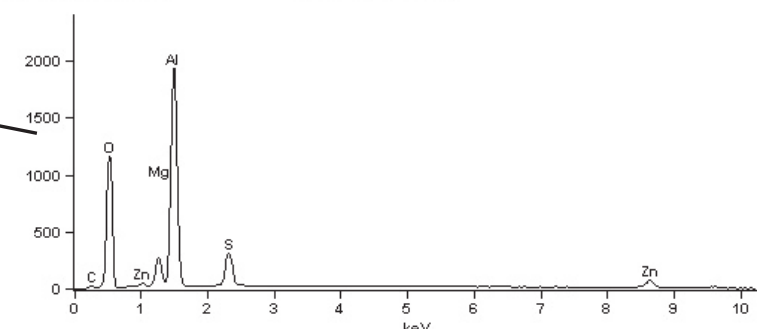

Rys. 4. Wyniki badań materiału rodzimego i złącza spawanego ze stopu AZ91 po 120 h badania odporności korozyjnej w 5\% roztworze kwasu $\mathrm{H}_{2} \mathrm{SO}_{4}$ : a) analiza fazowa XRD produktów korozji, b) warstwa produktów korozji, LM, c) mikroanaliza składu chemicznego produktów korozji na powierzchni

Fig. 4. The results of test of basic material and welding joint in AZ91 alloy after 120 hours of corrosion resistance in $5 \% \mathrm{H}_{2} \mathrm{SO}_{4}$ acid solutions: a) XRD phases analysis for corrosion products, b) corrosion products layer, LM, c) microanalysis of chemical composition of corrosion products on the surface 
bek w roztworze zmniejsza się do zera (rys. 2b). Zwiększenie stężenia roztworu kwasu $\mathrm{H}_{2} \mathrm{SO}_{4}$ do $5 \%$ powoduje wzrost ubytku masy spoiny i materiału rodzimego do poziomu ok. 18\% po $1 \mathrm{~h}$. Po upływie $120 \mathrm{~h}$ ubytek masy zawiera się w zakresie od $15 \%$ do $25 \%$ dla materiału rodzimego oraz odpowiednio od $18 \%$ do $24 \%$ dla spoiny (rys. $2 a$ ). Również w tym przypadku największa szybkość korozji jest po $1 \mathrm{~h}$ i wynosi zarówno dla spoiny, jak i materiału rodzimego $1,6 \mathrm{~g} /\left(\mathrm{cm}^{2} \cdot \mathrm{doba}\right)$. Szybkość ta po $6 \mathrm{~h}$ testu spada odpowiednio do $0,4 \mathrm{~g} /\left(\mathrm{cm}^{2} \cdot\right.$ doba $)$ dla materiału rodzimego i $0,2 \mathrm{~g} /\left(\mathrm{cm}^{2} \cdot\right.$ doba $)$ dla spoiny, a następnie jest bliska zeru (rys. 2b).

Korozja spoiny i materiału rodzimego złącza stopu AZ91 w roztworze $10 \%$ kwasu $\mathrm{H}_{2} \mathrm{SO}_{4}$ powoduje znaczący ubytek masy próbki zarówno ze spoiny (23\%), jak i z materiału rodzimego (34\%) już po $1 \mathrm{~h}$ testu (rys. 2a). Szybkość korozji jest większa dla materiału rodzimego i wynosi $2,9 \mathrm{~g} /\left(\mathrm{cm}^{2} \cdot\right.$ doba), a w spoinie $2,4 \mathrm{~g} /\left(\mathrm{cm}^{2} \cdot \mathrm{doba}\right)$. Obserwacja materiału po $6 \mathrm{go}$ dzinach dowodzi, że szybkość korozji materiału rodzimego spada do $0,5 \mathrm{~g} /\left(\mathrm{cm}^{2} \cdot \mathrm{doba}\right)$ i odpowiednio w spoinie $0,7 \mathrm{~g} /$ $/\left(\mathrm{cm}^{2} \cdot\right.$ doba). W dalszym okresie badań (do 120 h) szybkość korozji materiału rodzimego i spoiny jest bliska zeru (rys. 2b). Analiza ilości produktów korozji ujawnia, że przy tak dużym stężeniu roztworu kwasu $\mathrm{H}_{2} \mathrm{SO}_{4}(10 \%)$ rozrzut wyników uniemożliwia porównanie odporności korozyjnej materiału rodzimego i spoiny. Należy przyjąć, że jednocześnie materiał rodzimy (stop AZ91), jak również jego złącza w 10\% stężeniu kwasu $\mathrm{H}_{2} \mathrm{SO}_{4}$ są nieodporne na korozję elektrochemiczną.

Do oceny produktów korozji wykonano badania makrograficzne próbek przed chemicznym oczyszczeniem ich powierzchni. Wyniki obserwacji na mikroskopie stereoskopowym dla próbek z materiału rodzimego i ze spoiny złączy spawanych stopów magnezu zanurzanych w 1\% i 10\% roztworach kwasów $\mathrm{H}_{2} \mathrm{SO}_{4}$ odpowiednio przez $1 \mathrm{~h}$ i $120 \mathrm{~h}$ pokazano na rysunku 3.

Powierzchnia próbki materiału rodzimego ze stopu AZ91 po zanurzeniu w $1 \%$ roztworze $\mathrm{H}_{2} \mathrm{SO}_{4}$ przez $1 \mathrm{~h}$ pokryła się nierównomiernym szarym nalotem, natomiast po $120 \mathrm{~h}$ powierzchnia była pokryta jasną warstwą z nieregularnymi ciemnymi obszarami. Również po badaniu odporności korozyjnej stopu AZ91 w roztworze kwasu o stężeniu $10 \%$, po 1 h próbka pokryła się szarym nalotem z widocznymi punktami o kolorze metalicznym, natomiast po $120 \mathrm{~h}$ ujawniono jasny nalot $\mathrm{z}$ dużą ilością ciemnych plam. Podobne produkty korozji ujawniono na powierzchni próbek pobranych z obszaru spoiny złącza próbnego. Jednak w przypadku testu w $10 \%$ roztworze $\mathrm{H}_{2} \mathrm{SO}_{4}$ przez 120 h próbka pobrana ze spoiny uległa znacznemu roztworzeniu.

Uzupełnieniem wyników badań metalograficznych powierzchni próbek po ocenie odporności na korozję elektrochemiczną były badania metalograficzne złącza stopu AZ91 po $120 \mathrm{~h}$ testu odporności korozyjnej w $5 \% \mathrm{H}_{2} \mathrm{SO}_{4}$ oraz wyniki mikroanalizy składu chemicznego EDS i wyniki analizy fazowej XRD produktów korozji (rys. 4).

Analiza profilu próbki materiału rodzimego stopu AZ91 na zgładzie poprzecznym ujawniła silne rozwinięcie powierzchni charakterystyczne dla procesu rozpuszczania (5\% roztwór $\mathrm{H}_{2} \mathrm{SO}_{4}$ ) (rys. 4b). Głębokość wżerów korozyjnych była na poziomie $250 \mu \mathrm{m}$, a na ich powierzchni obserwowano produkty korozji (rys. 4c). Mikroanaliza składu chemicznego EDS wykazała, że są to produkty bogate w magnez, tlen, aluminium i siarkę, natomiast wyniki rentgenowskiej analizy fazowej wskazują, że produktami korozji są głównie wodorotlenki $\mathrm{Mg}(\mathrm{OH})_{2}, \mathrm{Mg}_{2} \mathrm{Al}(\mathrm{OH})_{7}$ oraz faza o wzorze stechiometrycznym $\mathrm{Mg}_{41,9} \mathrm{Al}_{59,9}$ (rys. 4a).

\section{Podsumowanie}

Przeprowadzone wstępne próby spawania i napawania odlewniczych stopów magnezu wykazały w przypadku spawania stopu AZ91 nieliczne pęknięcia i pęcherze na powierzchni spoiny. Stwierdzono, że stopy z grupy Mg-Al należy zaliczyć do trudno spawalnych, ze względu na ujawnione pęknięcia. Potwierdzają to informacje z odlewni o problemach spawalniczych związanych z naprawą odlewów z tych stopów. Wyniki badań odporności na korozję elektrochemiczną w roztworach kwasu $\mathrm{H}_{2} \mathrm{SO}_{4}$ materiału rodzimego i spoiny złączy spawanych stopów magnezu wskazują, że im wyższe stężenie roztworu, tym większa szybkość korozji oraz większy ubytek masy. Szybkość korozji próbek maleje wraz z czasem eksperymentu zarówno dla materiału rodzimego, jak i spoiny. Po 72 godzinach szybkość korozji spada poniżej 0,1g/( $\mathrm{cm}^{2} \cdot$ doba). Jest to spowodowane hamowaniem reakcji korozji w wyniku zobojętniania się roztworu testowego.

\section{Artykuł zrealizowany w ramach IV Kon-ferencji „Osiągnięcia Studenckich Kół Naukowych Uczelni Technicznych - STUKNUT'18”.}

\section{Literatura}

[1] Johnston S., Shi Z., Atrens A.: The influence of $\mathrm{pH}$ on the corrosion rate of high-purity Mg, AZ91 and ZE41 in bicarbonate buffered Hanks' solution, Corrosion Science, 101, 2015, pp. 182-192.

[2] Klag O., Wagner G., Eifler D.: Mechanical Properties of Friction Stir Welded $\mathrm{Mg} / \mathrm{Mg}(-)$ and $\mathrm{Mg} / \mathrm{Al}-\mathrm{Joints}$. Advanced Engineering Materials 12, 2010, pp. $1212-1219$

[3] Adamiec J.: The influence of construction factors on the weldability of AZ91E alloy, Archives of Metallurgy and Materials 56, 2011, pp. 769-778.

[4] Zettler R., da Silva M., Rodrigues S., Blanco A., dos Santos J. F.: Dissimilar Al to Mg Alloy Friction Stir Welds. Advanced Engineering Materials 8, 2006, pp. 415-421.

[5] Zhang T., Meng G., Shao Y., Cui Z., Wang F.: Corrosion of hot extrusion AZ91 magnesium alloy, Part II: Effect of rare earth element neodymium (Nd) on the corrosion behavior of extruded alloy, Corrosion Science 53, 2011, pp. 2934-2942.

[6] Kierzek, J. Adamiec: Evaluation of susceptibility to hot cracking of magnesium alloy joints in variable stiffness condition, Archives of Metallurgy and Materials 56, 2011, pp. 759-767.
[7] Huang J.: Corrosion behavior of AZ91 magnesium alloy for automobile engine, Jinshu Rechuli/Heat Treatment of Metals, 2014.

[8] Stopyra M., Adamiec J.: Microstructural stability of long-term annealed AZ91 magnesium alloy weld joint, vol. 782, 2014

[9] Abderrazak K., Salem W. B., Mhiri H., Bournot P., Autric M.: Nd:YAG Laser Welding of AZ91 Magnesium Alloy for Aerospace Industries. Metallurgical and Materials Transactions B. 40, 2009, pp. 54-61.

[10] Białobrzeski A., Czekaj E., Heller M.: Właściwości korozyjne stopów aluminium i magnezu przetwarzanych technologią odlewania ciśnieniowego, Archiwum Odlewnictwa. 2, 2002, s.1642-5308.

[11] Adamiec J., Roskosz S., Jarosz R.: Repair of magnesium alloy castings by means of welding and pad welding, Journal of Achievements in Materials and Manufacturing Engineering. 22, 2007, pp. 21-24.

[12] Kacalak W., Szafraniec F.: Metodyka doboru właściwości ściernic hybrydowych do obróbki stopów metali lekkich, Mechanik 90, s. 903-905, 2017. 